\title{
PATOLOGIAS EM ESTRADAS VICINAIS: A IMPORTÂNCIA DA MANUTENÇÃO E CONSERVAÇÃO DE VIAS RURAIS PARA O DESENVOLVIMENTO REGIONAL
}

\section{PATHOLOGIES IN VICINAL ROADS: THE IMPORTANCE OF MAINTENANCE AND CONSERVATION OF RURAL ROADS FOR THE REGIONAL DEVELOPMENT}

\author{
Alexandre Victor Silva Pinheiro, \\ ORCID: https://orcid.org/0000-0002-5815-8287 \\ Faculdade Presidente Antônio Carlos, Brasil. \\ E-mail: alexandrepinheiro982@gmail.com
}

Matheus Ferreira de Souza Silva, ORCID: https://orcid.org/0000-0002-1644-7670

Rede de Ensino Doctum, Brasil. E-mail: contato.matheusferreira@outlook.com

Pedro Emílio Amador Salomão, ORCID: https://orcid.org/0000-0001-9451-3111 Faculdade Presidente Antônio Carlos, Brasil. E-mail: pedroemilioamador@yahoo.com.br

\section{Resumo}

A malha viária é de extrema importância para o desenvolvimento de qualquer região ou país, especialmente no contexto econômico. O sistema rodoviário brasileiro é responsável pelo tráfego e movimentação de mais de $58 \%$ de todas as cargas no território nacional, sendo o meio de transporte mais significativo do país desde a aprovação do Plano Nacional de Viação em 1934. Estradas e rodovias são vias essenciais ao fluxo de insumos e bens, possibilitando a chegada, dos mesmos, das pequenas cidades, e produtores agrícolas, aos grandes centros urbanos. Este escoamento 
da produção (safra agrícola) é geralmente realizado por estradas vicinais ou de terra, por este motivo, a importância da conservação e manutenção destas vias. Este artigo tem como objetivo, por meio de pesquisas bibliográficas, expender a importância das estradas vicinais no escoamento da produção agrícola, abordando tópicos crucias como as características destas vias, CBR, patologias usuais, entre outros.

Palavras-chave: Estradas; Vicinais; Pavimentos.

\begin{abstract}
The road network is extremely important for the development of any region or country, especially in the economic context. The Brazilian road system is responsible for the traffic and movement of more than $58 \%$ of all cargo in the national territory, being the most significant means of transport in the country since the approval of the National Road Plan in 1934. Roads and highways are essential roads for the flow of inputs and goods, enabling small towns and agricultural producers to arrive in large urban centers. This flow of production (agricultural harvest) is generally carried out by side roads or dirt roads, for this reason, the importance of the conservation and maintenance of these roads. This article aims, through bibliographic research, to expand the importance of side roads in the flow of agricultural production, addressing crucial topics such as the characteristics of these roads, CBR, usual pathologies, among others.
\end{abstract}

Keywords: Roads; Vicinals; Floors. 


\section{INTRODUÇÃO}

As estradas vicinais (rurais), mais conhecidas como vias não pavimentadas, são vias municipais consideradas como principal meio de conexão entre áreas rurais e centros urbanos. Apesar das estradas vicinais corresponderem a uma extensa malha das estradas de rodagem, elas são muitas vezes esquecidas, geralmente deixam de recebem manutenções, e consequentemente desenvolvem problemas técnicos que dificultam o tráfego (VENESCAU, 2020).

A população que reside em locais mais afastados dos grandes centros urbanos depende diretamente das estradas vicinais para ter acesso à educação, atendimento médico, trabalho, comércio de mercadorias, e diversas outras atividades que só são empreendidas em áreas urbanas (CUNHA, 2011).

Uma estrada não pavimentada que não recebe manutenção preventiva, em curto prazo de tempo impreterivelmente irá apresentar uma série de patologias em sua camada de rolamento, como buracos, atoleiros, erosões e afloramentos de rochas, colocando em risco a segurança do trafego no trecho. Geralmente, estes problemas são causados pela deficiência da estrutura estradal, no sistema de drenagem, ou no revestimento da via.

A história das rodovias no Brasil está ligada ao processo de integração do território brasileiro, o qual se deu com as primeiras estradas rudimentares abertas pelos colonizadores portugueses, por imigrantes que se estabeleceram nas diversas regiões brasileiras, e pelos habitantes das pequenas vilas que no séc. XV e XVI se formavam em todo país. Por estas primitivas estradas de rodagem fazia-se a ligação entre as diversas regiões, criando as primeiras rotas comerciais nacionais, por onde eram transportados insumos e mercadorias (GUIMAR ÃES et al., 2004).

No Brasil o predomínio de estradas não pavimentadas é incontestável. “Conforme o levantamento do DNIT, o País conta com 1,7 milhão de quilômetros de estradas, porém, apenas 13\%, ou 221.820 quilômetros, estão pavimentados. O restante $87 \%$ das rodovias - não tem qualquer tipo de pavimentação.” (Brasilagro, 2015)

\section{ESTRADAS VICINAIS - CARACTERISTICAS TÉCNICAS ESSENCIAIS}


Para que uma estrada não pavimentada possa fornecer ao usuário condições de tráfego, algumas características técnicas devem ser analisadas, são elas:

- Índice de Capacidade de Suporte da camada do subleito, caracterizado também como CBR do subleito;

- Condições de Rolamento;

- Aderência.

\section{Índice de Capacidade de Suporte - CBR}

O Índice de Capacidade de Suporte (para uma estrada vicinal) é o fator que avalia a condição de camada estrutural para suportar as solicitações do tráfego. As deformações mais comuns devido à falta de capacidade de suporte são originadas por ondulações transversais e formação de trilhas de roda. Geralmente as estradas com baixa capacidade de suporte tendem a apresentar formação de lama em sua camada de rolamento ocasionada por pluviosidade intensa (MOURA, 2010).

Também é essencial evidenciar a importância camada do subleito, pois grande parte das patologias na estrutura da via tem a interferência dessa camada. Quando esta camada do subleito apresentar uma capacidade de suporte inferior a $2 \%$, o manual da pavimentação do DNIT (2006) recomenda a retirada de todo matérias com profundidade de 1 metro, e substituição do mesmo por outro com melhor resistência de suporte. Já para a camada da superfície os materiais mais indicados para garantir uma melhora no desempenho da capacidade de suporte e aderência são materiais granulares, como, saibro, cascalho ou RSCD (Resíduos Sólidos de Construção e Demolição).

Figura 1 - Conservação de estradas vicinais.

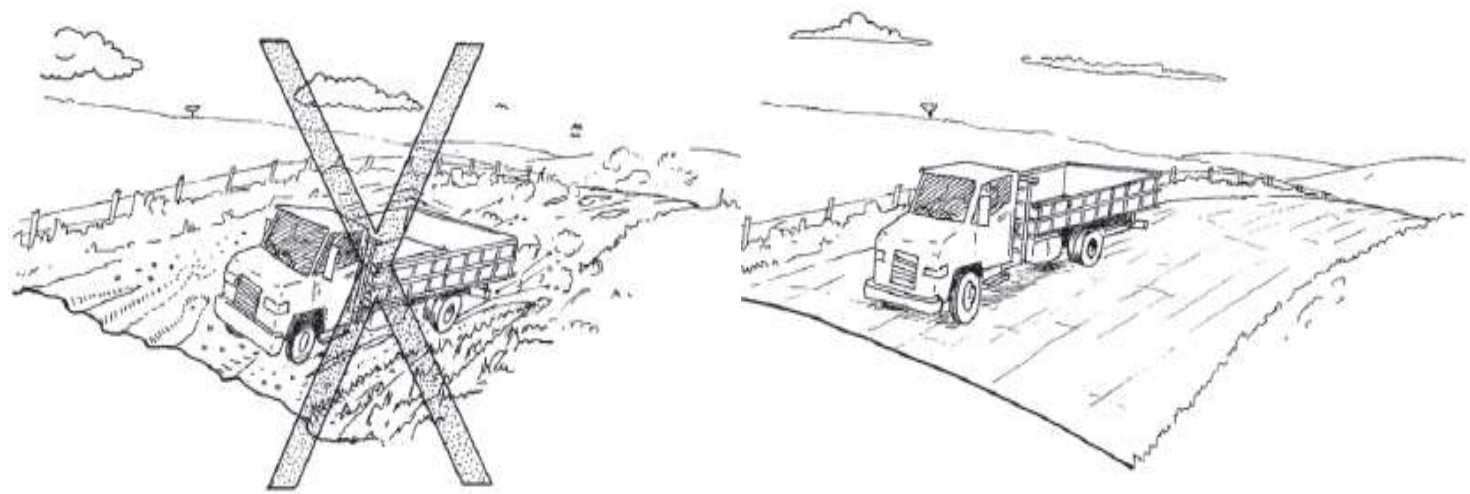


(Fonte: Manual de Conservação de Estradas Vicinais - ABGE - Associação Brasileira de Geologia de Engenharia e Ambiental, 2019)

\section{Condições de Rolamento e Aderência}

As condições de tráfego dizem muito sobre o estado físico da pista, que interfere diretamente no conforto e, principalmente, segurança do usuário da via. A falta de aderência em uma estrada não pavimentada gera más condições de atrito, aumentando risco de acidente, e outras ocorrências no contexto.

Popularmente falando, existem patologias usualmente identificáveis em vias não pavimentadas como buracos, materiais granulares soltos, pista escorregadia, etc. Os materiais granulares são os responsáveis pelas boas condições de atrito. No entanto, quando não compactados corretamente proporcionam as condições ideais para a falta de aderência na camada de rolamento.

O material ligante natural mais indicado é o saibro, e as operações de compactação visam garantir uma camada de revestimento que traga ao usuário conforto e segurança no uso da via.

Figura 2 - Tráfego em estradas vicinais.
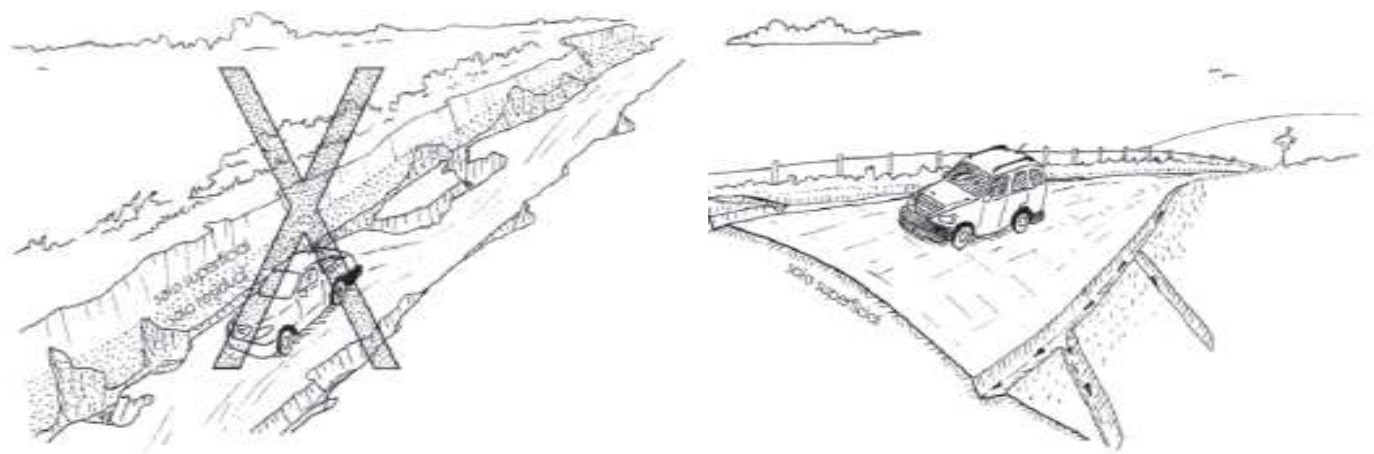

(Fonte: Manual de Conservação de Estradas Vicinais ABGE - Associação Brasileira de Geologia de Engenharia e Ambiental) 
Para a realização de uma manutenção de estradas não pavimentadas é recomendado que sejam realizados estudos geotécnicos da jazida onde será extraído o solo, a ser utilizado, para que sejam verificadas as propriedades e capacidade de suporte deste material, pois com base neste estudo será elaborado o planejamento para execução da manutenção de via. Os materiais que são extraídos em jazidas podem ser encontrados de diversas formas, sendo elas como areias, cascalhos, saibros, pedregulho.

Figura 3 - Seção Transversal de Estradas Não Pavimentadas.

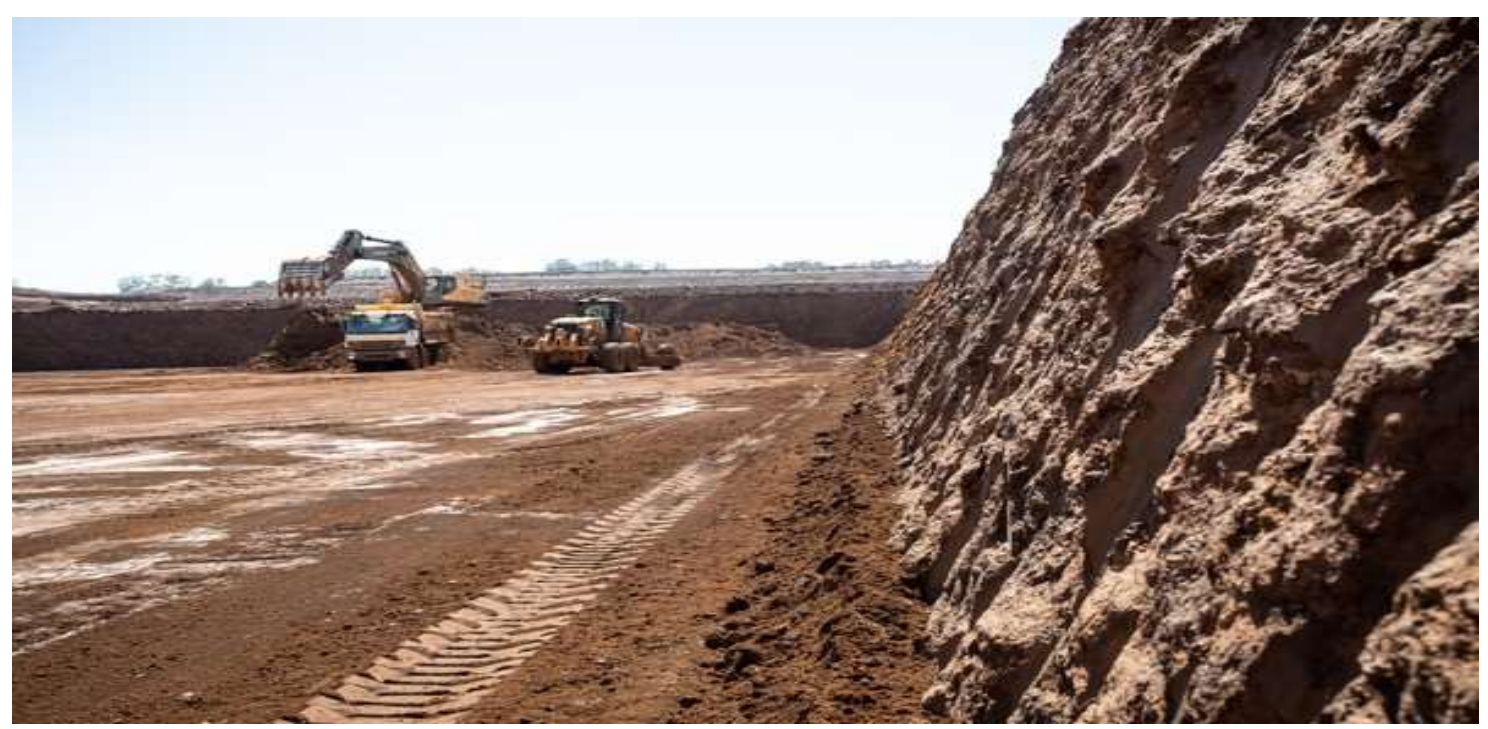

(Fonte: site g1.globo.com, acesso em 17/11/2020)

\section{Revestimento Primário}

O Revestimento Primário é uma camada granular composta por agregados naturais, podendo ser aplicada diretamente sobre o subleito e compactado até atingir a compressão desejada, com intuito de oferecer condições de tráfego confortáveis, mesmo sob condições climáticas adversas.

A finalidade da adição de argila no material granular é para atuar como um ligante e regularizar a superfície final na camada de rolamento. Já o uso do material granular é para aumentar o atrito das rodas do veículo com a pista. No entanto, existem normas que definem as dimensões ideais do material granula, sendo permitidas 
dimensões máximas ideais do material granular de $2,5 \mathrm{~cm}$.

$\mathrm{Na}$ natureza existem jazidas que podem ser utilizadas diretamente para a execução do revestimento primário, pois este material é composto por uma mistura já em proporções desejadas de materiais granulares e argilosos (cascalho, e saibro, por exemplo).

No entanto, é comum a necessidade de emprego de misturas especificas ou adequadas, uma vez que a maior parte das jazidas compostas por materiais granulares são escassas em argila (ligante), como é o caso de cascalho e pedregulhos de rio, e saibros grosseiros de rochas alteradas.

Figura 3 - Seção Transversal (estrutura) de Estrada Não Pavimentada.

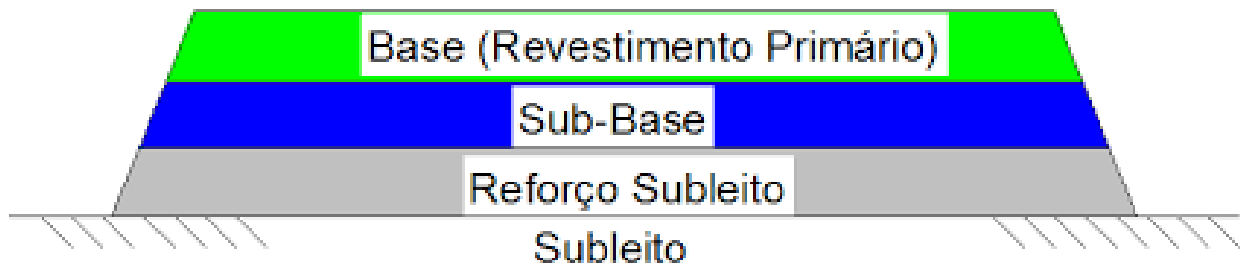

(Fonte: ROSSO et al.,2016).

\section{Sistema de Agulhamento}

O Agulhamento consiste no reforço do subleito, este processo executivo baseiase em escavação, inserção de material granular e compactação do mesmo.

Este método visa proporcionar durabilidade e desempenho satisfatório ao subleito, sendo indicado para situações onde a execução do revestimento primário se mostre problemática, muito custosa, ou até mesmo para estradas de terra de menor porte e com baixo volume de tráfego. Os materiais granulares mais indicados para o sistema de Agulhamento são cascalhos, brita com dimensão superior a $2,5 \mathrm{~cm}$, pedregulhos limpos e piçarras específicas.

\section{Mistura entre Materiais Argilosos e Arenosos}


A mistura de materiais argilosos e arenosos é uma técnica utilizada quando o subleito apresenta composição arenosa na maior parte da sua estrutura, provocando frequentemente problemas de deposição de camadas de areia na superfície da estrada e ao secar, compromete o tráfego. A técnica consiste na adição de cerca de $30 \%$ de argila (especifica) á base da via, propiciando a formação de uma camada de boa qualidade como pista de rolamento.

O objetivo desta adição é tornar o composto do revestimento primário (camada superficial) coesivo, evitando a ocorrencia de patologias infames como areiões e excesso de pó nas estradas (não pavimentadas). São previstas algumas dificuldades para misturar a areia com a argila, motivo pelo qual não é esperada uma perfeita homogeneização, porém, esse fato não implica na perda de eficiência da solução.

\section{Sistema de Drenagem}

O sistema de drenagem possui uma grande importância para o escoamento das águas pluviais. Este sistema consiste em uma estrutura construída (geralmente) á margem das estradas que tem como função principal coletar e conduzir as águas provenientes do escoamento superficial da própria estrada para locais apropriados. Estes canais devem ser corretamente instalados, com a finalidade de drenar a água das estradas, evitando em períodos com chuvas intensas, que a mesma venha causar danos na via e dificuldade de trafego.

\footnotetext{
"Um sistema de drenagem bem projetado, construído e conservado, portanto, garante tanto a segurança dos usuários da rodovia, reduzindo consideravelmente o número de acidentes, quanto o aumento da durabilidade do pavimento, de elementos estruturais e da integridade dos taludes de corte e aterro." (Grupo Sampietro, 2020)
}

Figura 4 - Sistema de Drenagem em Estrada não Pavimentada.

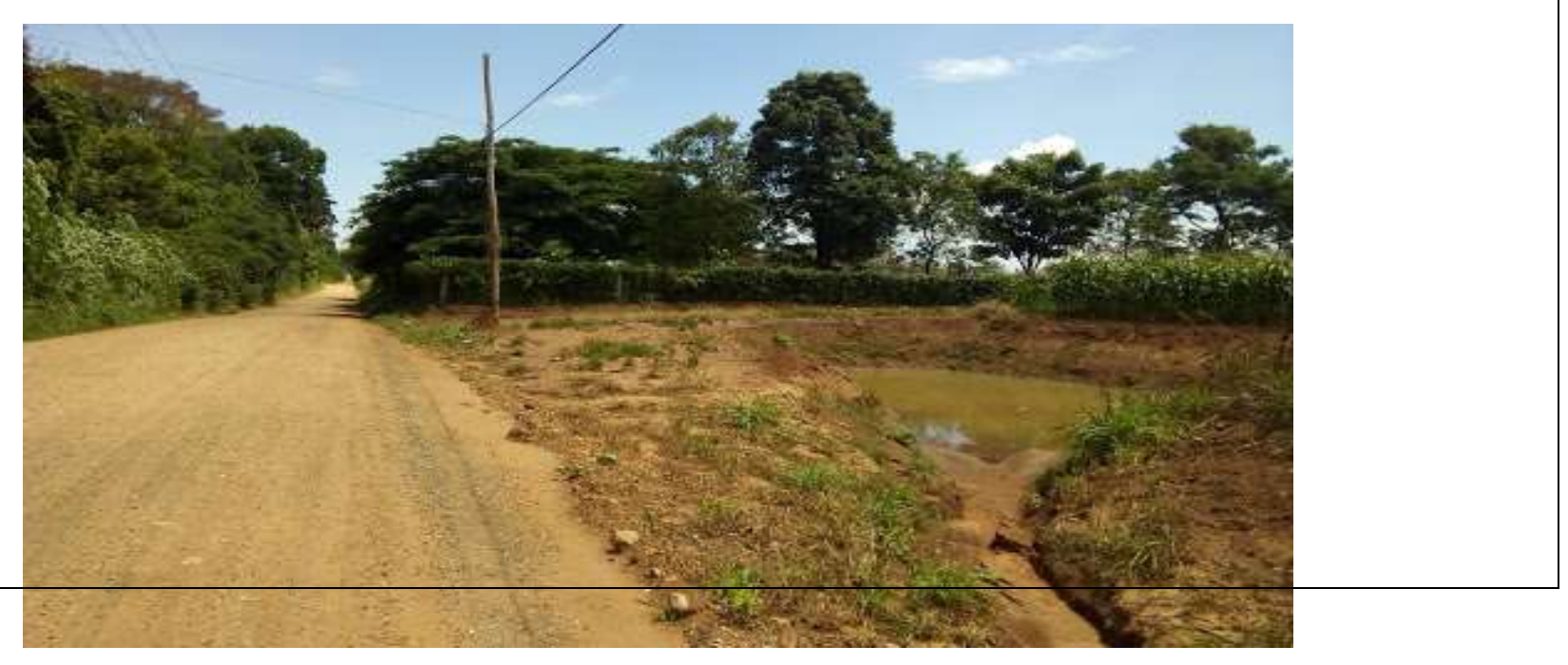


(Fonte: CODASP - Companhia de Desenvolvimento Agrícola de São Paulo)

\section{Características Gerais}

Segundo o Departamento Nacional de Infraestrutura de Transportes - DNIT (apontado na Tabela 1) a extensão geral ficou estável entre 1,72 e 1,77 milhão de quilômetros de 2005 a 2015, indicando pequena retração de $0,3 \%$ ao ano no período. A malha pavimentada, que representava $12,2 \%$ do total em 2015 , cresceu $0,2 \%$ ao ano entre 2005 e 2015, enquanto a malha não pavimentada, que representava 78,6\% do total em 2015, registrou retração de $0,3 \%$ ao ano no período. O restante é constituído pela malha rodoviária planejada, que já estava em construção em cada ano, mas não estava em operação.

O SmartArt 1 mostra a distribuição destas malhas em 2015 e a participação de cada categoria no total da extensão rodoviária.

Tabela 1 - Malha rodoviária (pavimentada e não pavimentada).

\begin{tabular}{|c|c|c|c|c|}
\hline \multicolumn{5}{|c|}{ MALHA RODOVIÁRIA } \\
\hline$\underline{\text { Ano }}$ & Planejada & Não Pavimentada & Pavimentada & Total \\
\hline 2005 & 168.124 & 1.391 .868 & 205.706 & 1.765 .698 \\
\hline 2010 & 154.357 & 1.368 .227 & 212.738 & 1.735 .322 \\
\hline 2015 & 157.561 & 1.352 .464 & 210.619 & 1.720 .643 \\
\hline$\underline{\text { Variação Anual }}$ & $-0,6 \%$ & $-0,3 \%$ & $0,2 \%$ & $-0,3 \%$ \\
\hline
\end{tabular}

(Fonte: Departamento Nacional de Infraestrutura de Transportes (DNIT) / Ministério dos Transportes, Portos e Aviação Civil)

SmartArt 1 - Malha viária brasileira, por tipo, em quilômetros e porcentagem do total, 2015. 


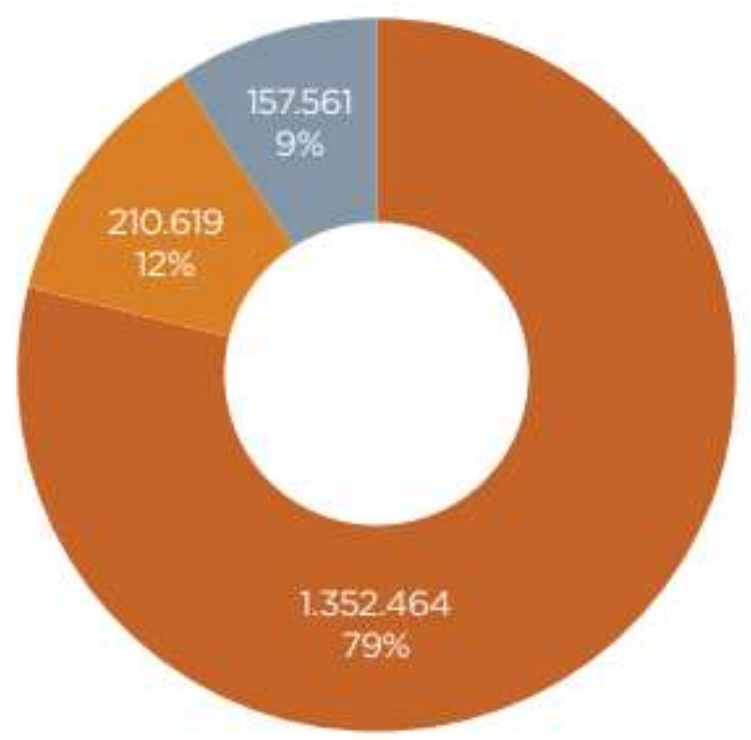

Năo pavimentada

Pavimentada

Planejada

(Fonte: Departamento Nacional de Infraestrutura de Transportes (DNIT) / Ministério dos Transportes, Portos e Aviação Civil)

\section{PATOLOGIAS EM ESTRADAS RURAIS - CAUSAS E SOLUÇÕES}

De acordo com o IPT (Instituto de Pesquisas Tecnológicas) as patologias (problemas) mais recorrentes em estradas vicinais são:

- Carência de capacidade de suporte no subleito;

- Superfície de rolamento defeituosa;

- Sistema de drenagem ineficiente.

Vale resaltar que apesar de não ser um problema primário, a ineficiência do sistema de drenagem sempre acarreta problemas decorrentes, como desgaste, 
Revista Multidisciplinar do Nordeste Mineiro, 2020/02 ISSN 2178-6925

deslizamentos, entre outros.

SmartArt 2 - Patologias mais comuns em estradas de terra.
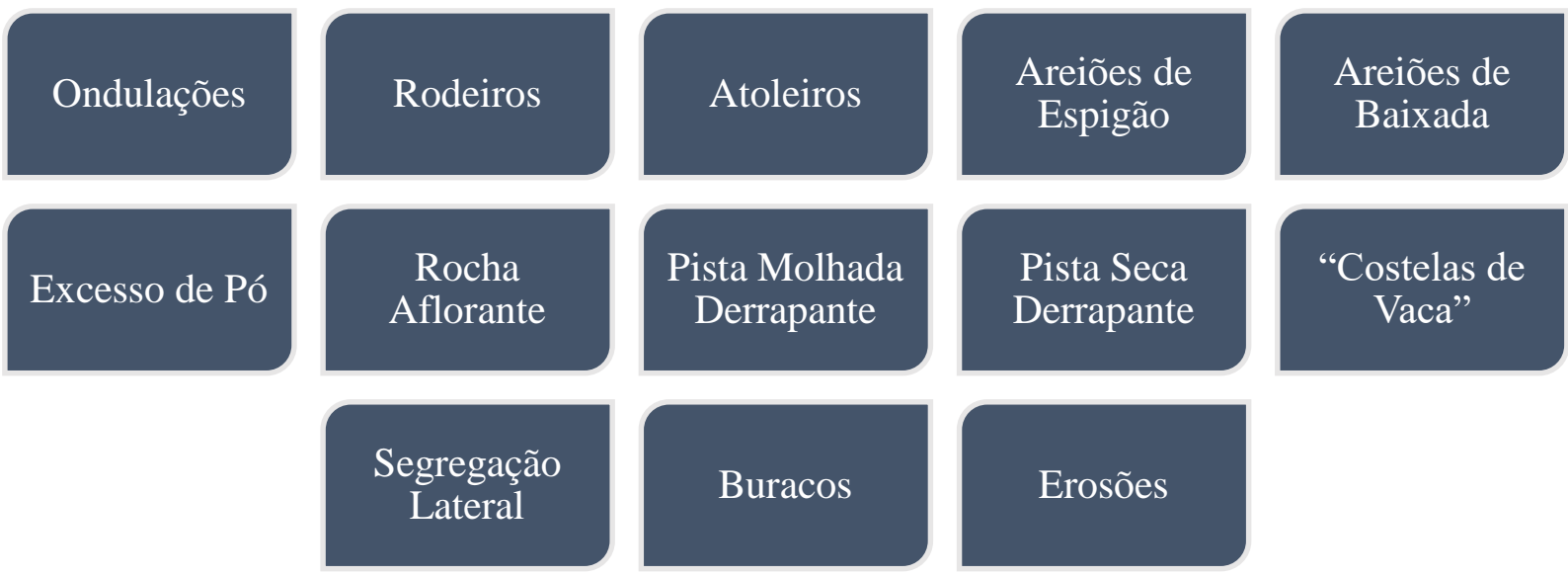

(Fonte: DOS SANTOS, et al., 2019)

\section{Ondulações, Rodeiros e Atoleiros}

* Causa: Subleito insustentável, com baixa capacidade de suporte, e ineficiência ou ausência de sistema de drenagem.

* Reparo: Bombeamento e/ou drenagem da água do local (através de valetas, por exemplo), execução de camada de reforço e realização do método do revestimento preferido sobre a mesma.

Figura 5 - Atoleiro em estrada vicinal.

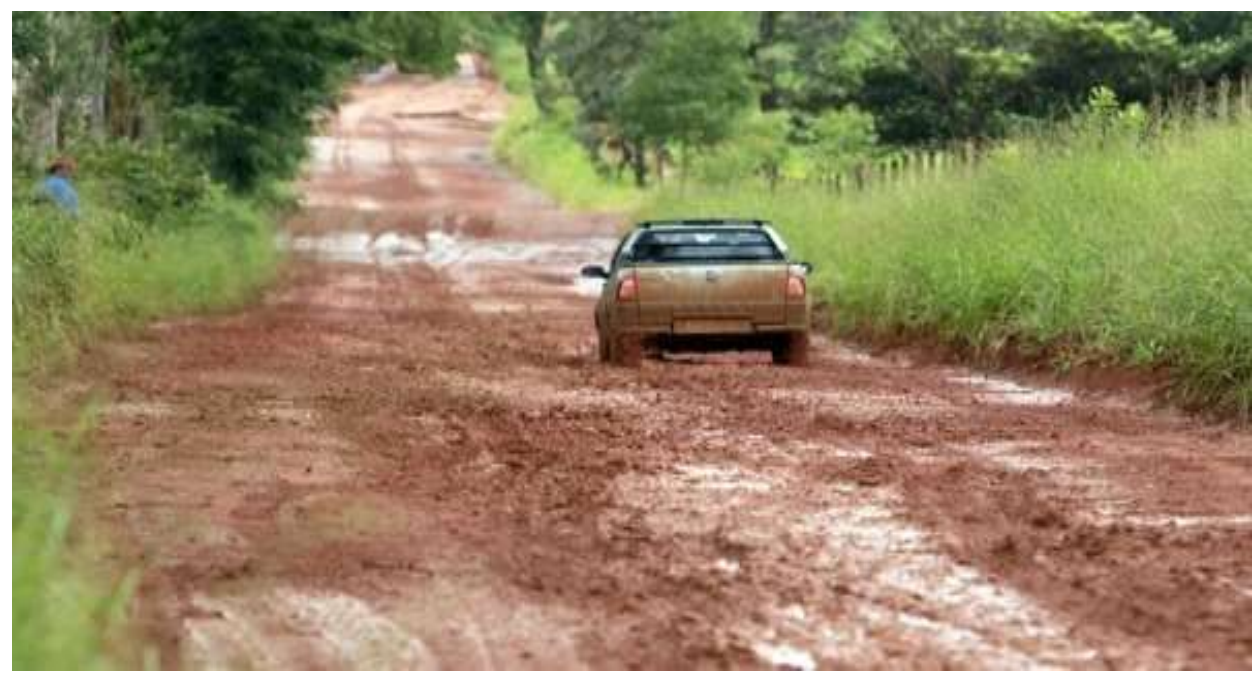


(Fonte: site gcn.net.br, acesso em 16/11/2020)

\section{Areiões de Espigão}

Causa: Recorrente em locais com solos arenosos ausentes de argilas, os areiões são resultantes do processo de lavagem do revestimento superficial (geralmente pela ação de águas pluviais) aliado ao tráfego, formando assim, uma camada de areia solta que depois de seca compromete a segurança do transito.

Reparo: Empregar o uso de argila no local, através da mistura, da mesma, com a areia do pavimento original (revestimento primário - proporção 1:2,5) ou utilização de outra técnica que garanta propriedades semelhantes á pista.

\section{Areiões de Baixada}

* Causa: Fenômeno similar ao ocorrente em Areiões de Espigão, difere no tipo de relevo em questão. A camada de areia, neste caso, é trazida pela água de trechos a montante ocasionando a patologia.

* Reparo: Mesma metodologia recomendada nos Areiões de Espigão. A contenda á erosão é primordial, já que existe susceptibilidade de novas patologias, ou agravamento da presente devido a características do relevo no local (baixada).

Figura 6 - Areiões em estrada vicinal.

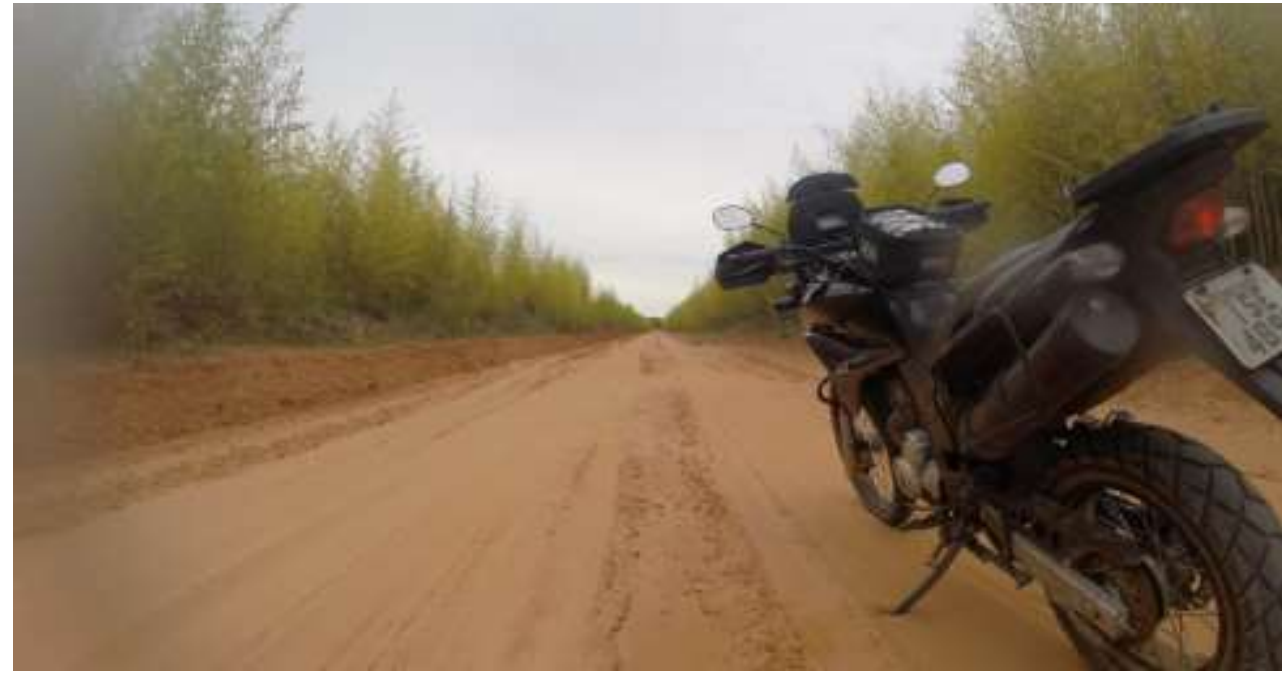


(Fonte: site tripadvisor.com.br, acesso em 16/11/2020)

\section{Excesso de Pó}

* Causa: Nuvens abundantes em partículas finas (não coesivas), que colocam em risco o tráfego, devido a fatores como redução da visibilidade no trecho. Causam diversos malefícios á saúde dos usuários do mesmo, e reduzem a vida útil dos veículos devido á impregnação de fuligem nos componentes mecânicos.

Reparo: Aplicação de revestimento superficial selante (composto argiloso ou escória de aciaria, por exemplo). Esta patologia é acentuada em solos suscetíveis como os finos siltosos, sendo essencial reforçar o subleito para evitar novas ocorrências.

\section{Rocha Aflorante}

Causa: Fenômeno decorrente da dissipação de grandes quantidades de blocos rochosos, erosão e patrolamento ativo da via, que expõe o leito rochoso, tornando a via inviável ao tráfego. Esta patologia pode ser dividida em duas categorias: Leito irregular com pontas de pedra, e Leito irregular de laje com buracos.

Reparo: Execução de camada (revestimento) primária de cobertura.

\section{Pista Molhada Derrapante}

Causa: Acontece em trechos com pouca aderência, devido á presença de água pluvial ou umidade aliadas á abundância de argila na composição do pavimento. Tornando a via intransitável (especialmente em trechos inclinados), suscetível a escorregamentos e, consequentemente, colocando em risco a segurando dos usuários da mesma. 
Reparo: Execução de agulhamento de componentes granulares sobre o leito.

Figura 7 - Trecho com pista molhada.

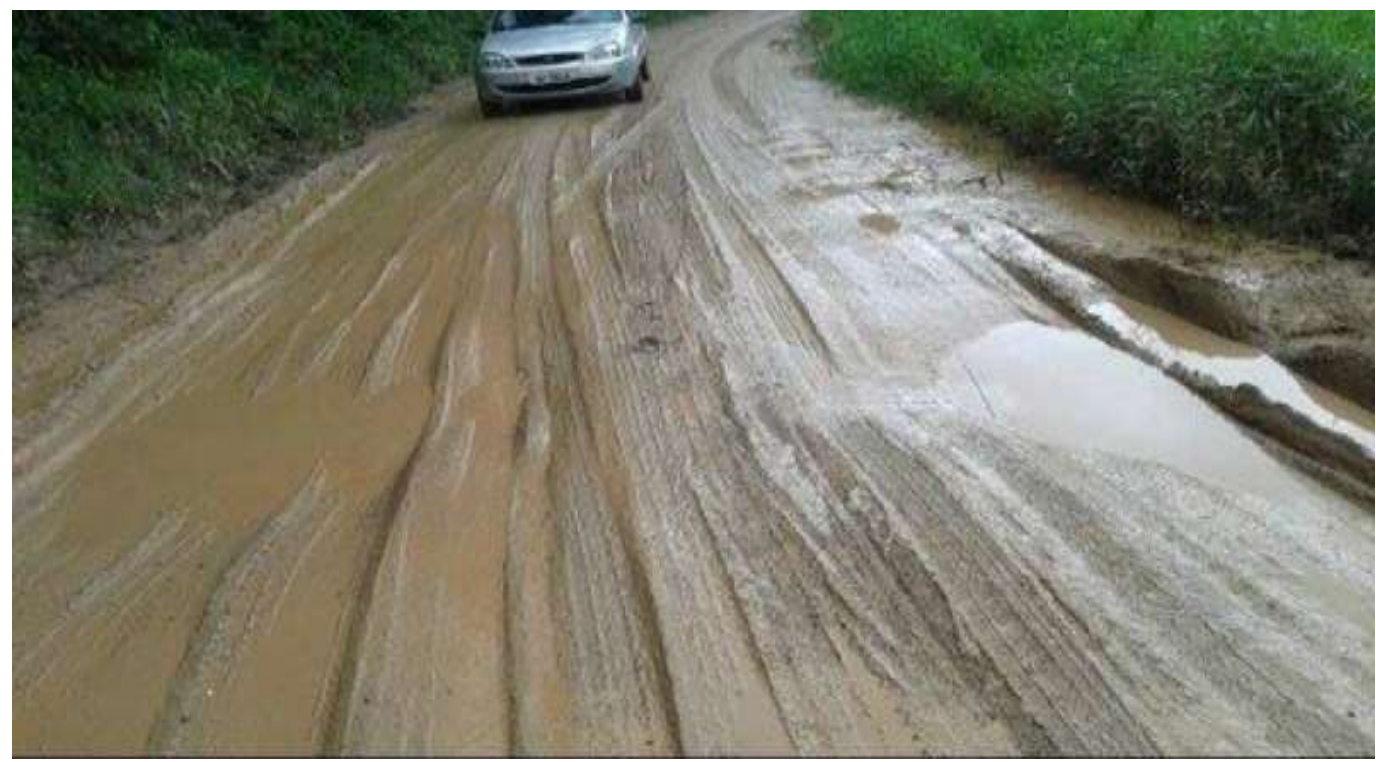

(Fonte: site almanaquesos.com, acesso em 16/11/2020)

\section{Pista Seca Derrapante}

Causa: Ocorre em trechos onde o processo de "encascalhamento" foi realizado com materiais granulares de dimensões inapropriadas. Esta patologia geralmente acontece em áreas onde o solo (leito original) é composto por partículas muito pequenas ou vias onde o método de tratamento foi realizado incorretamente (sem material ligante).

* Reparo: Execução de "agulhamento" corretamente.

\section{Costelas de vaca / Corrugações}

Causa: Mesmo tipo de patologia que a citada acima (Pista Seca Derrapante), porém neste caso existe o acumulo de resíduos em formas ondulares transversais, gerando desconforto ao trafegar. 
Reparo: A solução é simples, troca do revestimento primário (superficial) por um revestimento com propriedades diferentes ou de granulométrica apropriada (agulhada no leito).

Figura 8 - Corrugações em estrada vicinal.

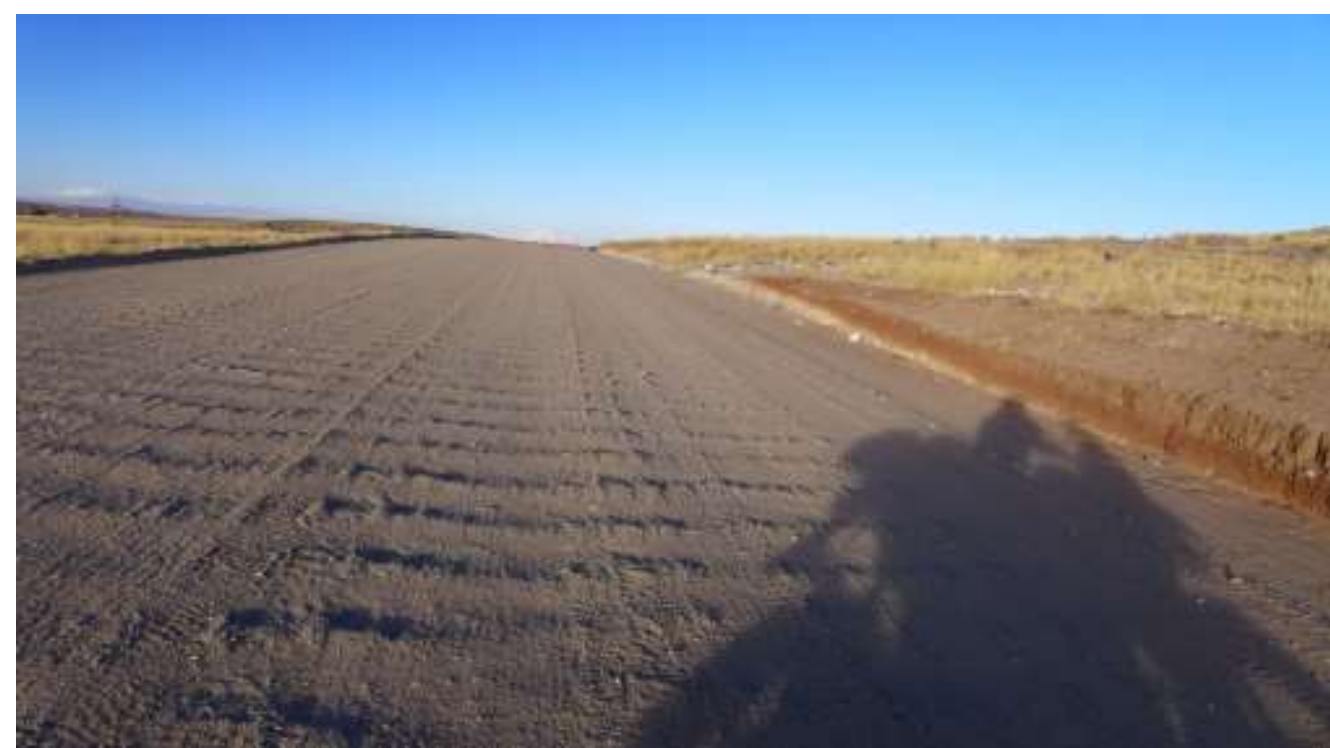

(Fonte: site viagemkikobarros.blogspot.com, acesso em 17/11/2020)

\section{Segregação Lateral}

Causa: Lançamento e depósito de material granular / partículas (faltantes de ligante) nos bordos da via.

* Reparo: Existem três tipos de tratamentos distintos que proporcionam características ideias para sanar a patologia, são eles o "agulhamento", troca do revestimento superficial e aplicação de ligante no trecho.

\section{Buracos}

Causa: Esta patologia ocorre devido a um conjunto de problemas (recorrentes) na via. O trafego intenso no local eduz e desgasta o pavimento principalmente onde existe água aculumada (empoçamento). Ou seja, fatores como empoçamento 
(deficiência no sistema de drenagem ou ausência de abaulamento transversal na pista), pavimento mal executado (sem tratamento primário) e trafego intenso, são os agentes responsáveis pelo surgimento e agravamento desta patologia.

Reparo: A solução é a prevenção e tratamento dos problemas citados acima. Implantação de um sistema de drenagem adequado com abaulamento da pista, drenos e sangradouros. Realizar o tratamento do revestimento primário, equilibrando os diferentes materiais granulares de forma a garantir propriedades essenciais ao pavimento, como resistência e estabilidade. A medida corretiva, no entanto, é cobrir o buraco com material adequado á via.

Figura 9 - Cobrimento de buracos em estrada vicinal.

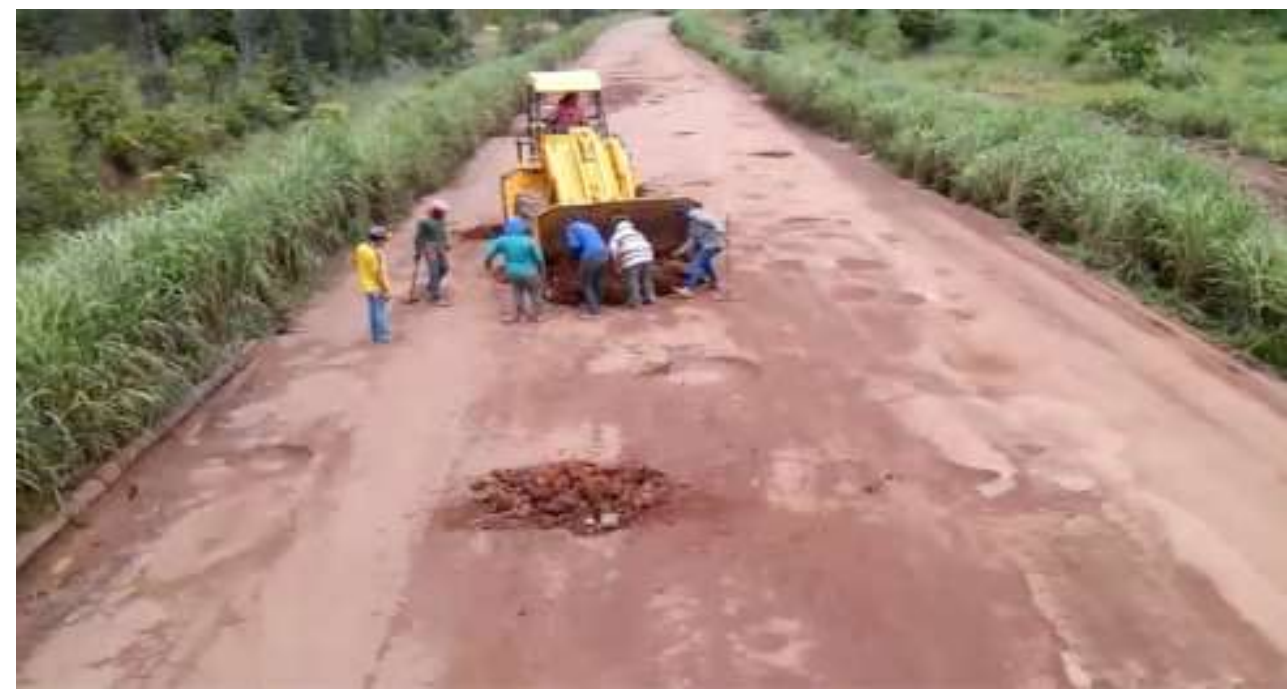

(Fonte: site g1.globo.com, acesso em 17/11/2020)

\section{Erosão}

Os processos erosivos, ou erosões, são as patologias que mais afetam estradas rurais. Com o seu potencial destrutivo, este problema, quase sempre, interrompe por completo o trafego no local. Ocorre em estradas, mas são originadores de outras patologias geológicas como barrancos, assoreamentos (lagos e rios), voçorocas, entre outros.

Esta patologia mostra a importância de um sistema de drenagem eficaz que capta, conduza e destine corretamente a água, já que estradas pavimentadas e não 
pavimentadas (neste caso) acentuam, através do escoamento, a energia das águas pluviais, esta força é diretamente proporcional ao poder erosivo das mesmas.

\begin{abstract}
“A erosão provocada pela água no leito e nas margens das estradas rurais de terra está intimamente relacionada à má drenagem, sendo um dos principais fatores para sua degradação. Para que o sistema de drenagem seja feito de forma adequada é necessário o conhecimento da erodibilidade, capacidade de infiltração de água no solo e adoção de práticas mecânicas de elevação do greide e interceptação de águas através de dispositivos de captação." (CASARIN, 2008)
\end{abstract}

Causas: A causas são as citadas acima, deficiência no sistema de drenagem e o profundamento do leito da via atingindo solos mais erodíveis.

Prevenção: Fortalecimento do sistema de drenagem existente, execução de abaulamento ( $3 \%$ de declividade) e execução de sangras para retirar água da via e evitar empoçamentos.

Reparo: Implantação de um sistema de drenagem eficaz, cobrimento das zonas afetadas com material argiloso (compactado), e reestruturação do revestimento primário, finalizando com compactação.

Figura 10 - Erosão em via não pavimentada.

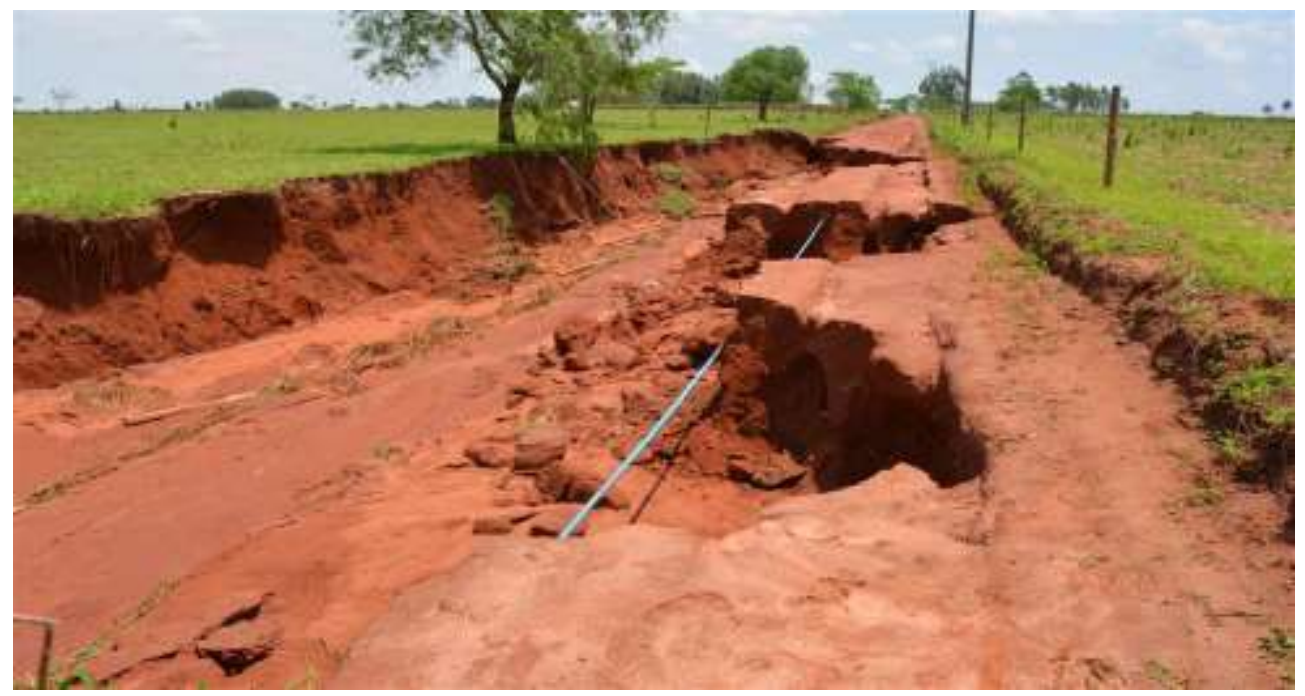

(Fonte: site conesulemfoco.com.br, acesso em 16/11/2020)

Sistemas / Mecanismos de Prevenção á Erosão 
SmartArt 3 - Mecanismos de Prevenção á Erosão.

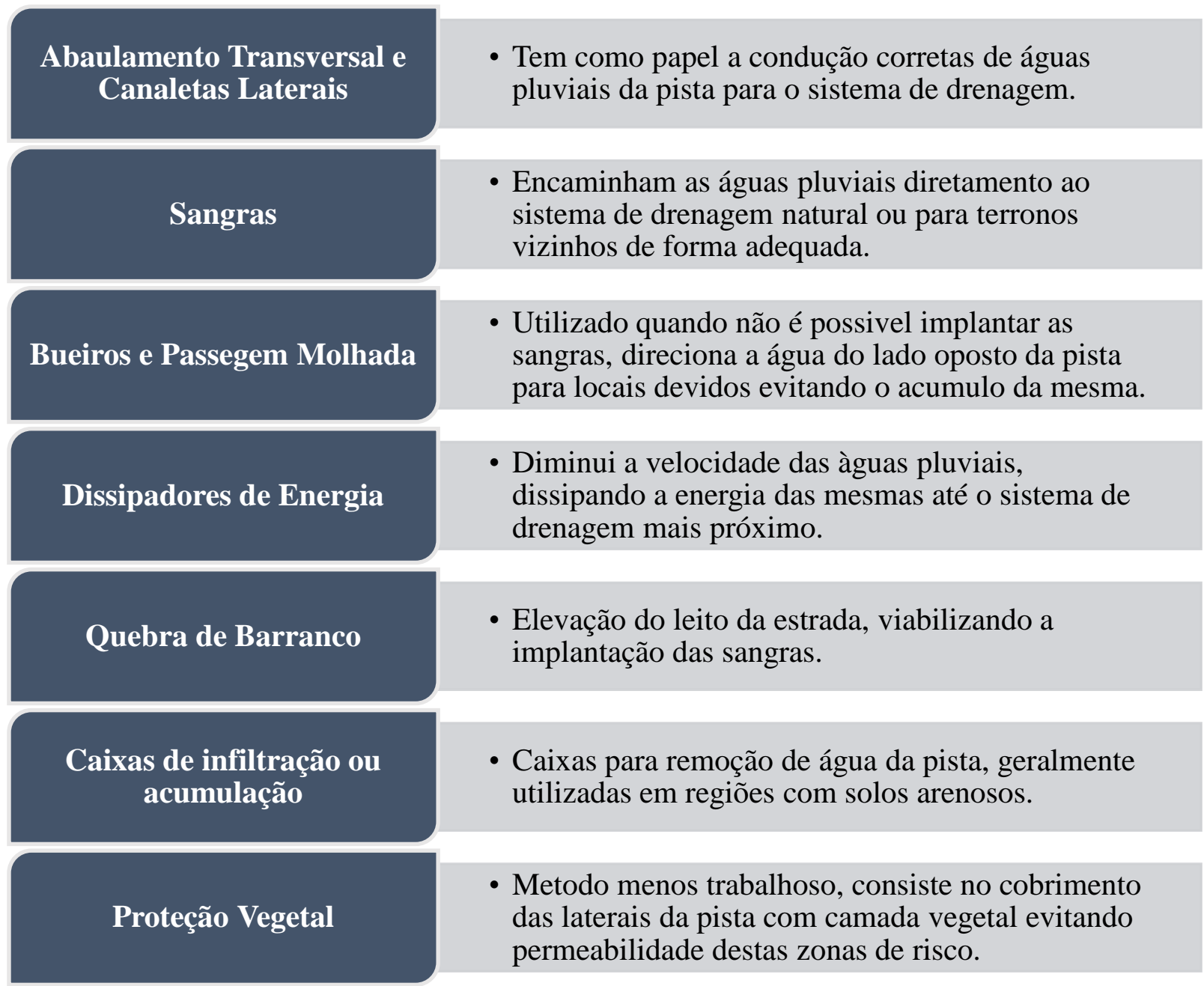

(Fonte: autor, realizado em 16/11/2020)

\section{IMPORTÂNCIA DA PAVIMENTAÇÃO CORRETA DA CONSERVAÇÃO E MANUTENÇÃO DE ESTRADAS VICINAIS}

A importância das estradas vicinais transcende o escoamento da produção rural. Contemporaneamente falando, cada vez mais é notória a relevância das estradas vicinais para o mercado nacional e global. A conservação e a pavimentação das mesmas são fundamentais para todos os segmentos existentes (sociais, econômicos, etc.).

A eficiência do escoamento da produção, do transporte de insumos e 
principalmente viabilidade da busca por serviços básicos nas cidades, depende diretamente do bom estado destas vias. O abastecimento das cidades, consorciação da produção e geração de emprego, são só alguns dos fatores que estão diretamente relacionados.

A explosão demográfica e globalização acelerada têm deixado cada vez mais sobrecarregados e exigentes sistemas como o de saúde, produção, locomoção, o que exige infraestrutura adequada para o bom e eficiente trafego de mercadorias (insumos) dos produtores aos comércios e agroindústrias no geral. Garantindo o escoamento incessante independente da época do ano ou clima.

\footnotetext{
"O sistema viário funciona em perfeita sincronia, onde as estradas vicinais permitem a chegada de insumos aos centros produtivos e também a saída de produtos e as rodovias pavimentadas são responsáveis pela distribuição dos mesmos ao longo do país." (VENESCAU, 2020)
}

Este processo é de extrema importância, pois vai determinar um dos fatores mais importantes em qualquer operação econômica, a frequência de aquisição. A facilidade e assiduidade do transporte, engendra o custo dos produtos afetando o comercio em supermercados, mercados e feiras locais.

"Desta forma estradas em boas condições de tráfego são importantes para a economia agrícola, para a convivência social e o acesso a recursos fundamentais da sociedade" (GRIEBELER et al., 2009).

Figura 11 - Escoamento da produção rural no Brasil. 


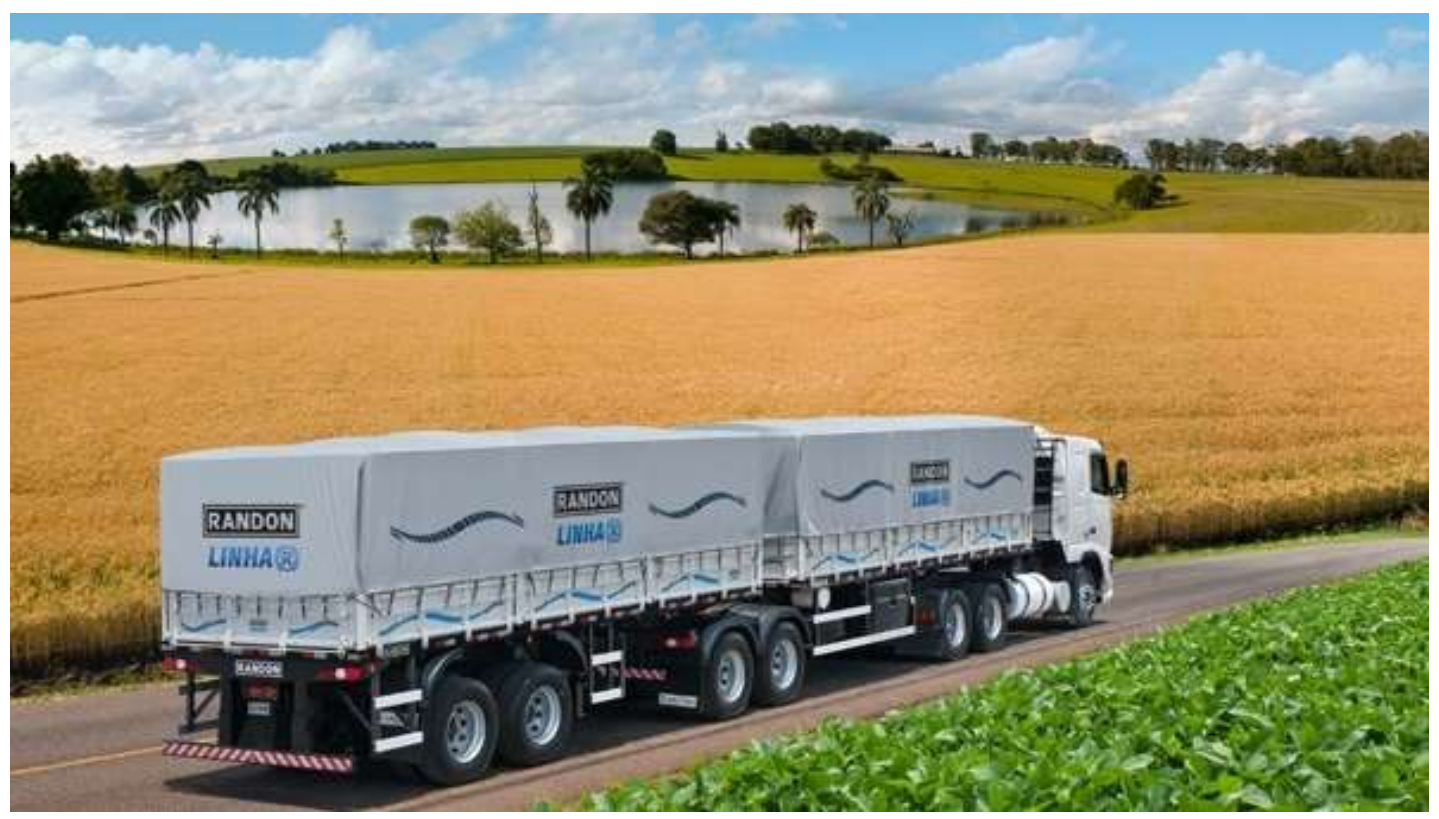

(Fonte: site ruralpecuaria.com.br, acesso em 17/11/2020)

\section{CONCLUSÃO}

Esse artigo buscou elucidar a importância das estradas vicinais para o desenvolvimento econômico regional. Apesar da desatenção, vias rurais são imprescindíveis para o funcionamento do sistema viário nacional. As estradas de terra geralmente são o ponto de partida por onde é realizado o escoamento da produção agrícola para as grandes feiras, mercados e agroindústrias, além de serem terem papael fundamental no acesso a aserviços basicos como saude e educação de populações que vivem em zonas rurais ou periféricas. Este tipo de via pode apresentar revestimento em sua estrutura de rolamento ou não, sendo primordial a execução do método de tratamento adequado da pista para garantir durabilidade á mesma, visando sempre a segurança e conforto dos usuários. Atraves deste estudo, foi possivel verificar que a maioria das patologias, ocorrem precisamente devido ao desgaste e má execução desta camada superficial. É de suma importância, para a industria, e para a população que reside em zonas rurais, que as estradas vicinais (vias de acesso) estejam em boas condições de rolamento, pois a base da piramide de escoamento é justamente a conjuntura do transporte de insumos, afetando diretamente o preço e qualidade do 
produto final.

\section{REFERÊNCIAS BIBLIOGRÁFICAS}

BAESSO, D. P. GONÇALVES, F. L. R. Estradas rurais: técnicas adequadas de manutenção. Florianópolis: DER 2003. 204 p.

\section{Brasilagro. 2015. BRASIL TEM APENAS 13\% DAS ESTRADAS} PAVIMENTADAS.

em:

https://brasilagro.wordpress.com/2015/11/09/brasil-tem-apenas-13-das-estradaspavimentadas/. Acesso em: 17/11/2020;

CASARIN, Rui Donizete. 2008. Controle de erosão em estradas rurais não pavimentadas, utilizando sistema de terraceamento com gradiente associado a bacias de captação. Disponível em: https://repositorio.unesp.br/handle/11449/93814. Acesso em: 17/11/2020;

CUNHA M. C. Avaliação da eficácia das caixas de contenção de sedimento em estradas rurais não pavimentadas na Bacia do Rio Das Pedras, Guarapuava-Pr, Guarapuava, Universidade Estadual do Centro Oeste, 2011.

DENER - Departamento Nacional de Estradas de Rodagem. Conservação de estradas não pavimentadas. Instituto de Pesquisa Rodoviária, Departamento Nacional de Estradas de Rodagem, Rio de Janeiro - RJ, 1981.

DNIT. 2006. Manual de Pavimentação. Publicação IPR - 179. Ministério dos transportes. Departamento Nacional de Infraestrutura de Transportes, Instituto de pesquisas rodoviárias.

GRIEBELER, N. P.; PRUSKI, F. F.; SILVA, J. M. A. Controle da erosão em estradas não pavimentadas. p. 166-215. In: PRUSKY, F. F. Conservação de solo e água: Práticas mecânicas para o controle da erosão hídrica. 2ª Edição. Editora UFV. 2009. $279 \mathrm{p}$. 
Grupo Sampietro. 2020. A importância do SISTEMA DE DRENAGEM em rodovias. Disponível em: https://www.gruposampietro.com.br/post/a-importancia-dosistema-de-drenagem-em rodovias\#: :text=A\%20principal\%20fun\%C3\%A7\%C3\%A30\%20da\%20drenagem,o\% 20rebaixamento\%20do\%20len\%C3\%A7ol\%20fre\%C3\%A1tico. Acesso em: $15 / 11 / 2020$

GUIMARÃES, C. J. DROPA, M. M. JORGE, M. A. P. Dos caminhos de circulação às rodovias de integração. Ponta Grossa - PR, 2004.

MOURA, Edson De. 2010. Estudo de Deformação Permanente em Trilha de Roda de Misturas Asfálticas em Pista e em Laboratório. Disponível em: https://www.teses.usp.br/teses/disponiveis/3/3138/tde-17082010

094223/publico/Tese_Edson_de_Moura.pdf. Acesso em: 17/11/2020;

ROSSO, L. T.; QUEVEDO, J. C; TAPAHUASCO, W. F. C. 2016. Estudo de Aplicabilidade dos Métodos de Dimensionamento e Avaliação Condicional de Serventia para Rodovias não Pavimentadas da Região da Fronteira Oeste do Estado do Rio Grande do Sul. Disponível em: https://plataforma.swge.com.br/PROCEEDINGS/PDF/GJ-03-0006.pdf. Acesso em: 16/11/2020;

VENESCAU, Ricardo. 2020. Importância das Estradas Vicinais. Disponível em: http://engenhariarodoviaria.com.br/importancia-das-estradas-vicinais/. Acesso em: 17/11/2020; 